\title{
Bilateral acute visual loss from Rathke's cleft cyst apoplexy in a patient with dengue fever
}

\section{Perda visual aguda secundária a apoplexia de cisto de Rathke em paciente com dengue}

\author{
Ana Cláudia De Franco Suzuki ${ }^{1}$, Rafael Barbosa de Araújo ${ }^{1}$, Eduardo Cunha de Souza ${ }^{1}$, Mário Luiz Ribeiro Monteiro ${ }^{1}$
}

\section{ABSTRACT}

Hemorrhagic complications of optic pathway diseases are extremely rare causes of acute visual loss associated with dengue fever. In this paper we report a patient presenting with dengue fever and bilateral acute visual loss caused by chiasmal compression due to Rathke's cleft cyst apoplexy. Considering the importance of early diagnosis and treatment to visual recovery, apoplexy of sellar and suprasellar tumors should be considered in the differential diagnosis of patients with acute visual loss and dengue fever.

Keywords:Visual disorders/etiology; Dengue/complications; Retinal hemorrhage; Pituitary apoplexy; Optic chiasm; Humans; Case reports

\section{RESUMO}

Complicações hemorrágicas de doenças da via óptica são causas extremamente raras de perda aguda de visão em pacientes com denque. Nesse trabalho, documentamos um caso de paciente com dengue apresentando perda de visão bilateral aguda secundária a compressão quiasmática por quadro hemorrágico em cisto de Rathke. Considerando a importância do diagnóstico e tratamento precoces para um bom prognóstico visual, a apoplexia de tumores da região selar e suprasselar deve ser incluída como um raro, porém importante, diagnóstico diferencial de perda visual aguda nesses pacientes.

Descritores: Transtornos da visão/etiologia; Dengue/complicações; Hemorragia retiniana; Apoplexia hipofisaria; Quiasma óptico; Humanos; Relatos de casos

\section{INTRODUCTION}

Dengue fever (DF) is a viral infection disease endemic in tropical and subtropical areas; it is caused by four different virus serotypes. Its clinical features vary from asymptomatic infection to critical systemic disease. One of the more severe forms of the disease is dengue hemorrhagic fever, characterized by fever, evidence of a hemorrhagic event or a positive tourniquet test, low platelets levels ( $\leq 100,000$ cells/ $\mathrm{mm}^{3}$ ) and evidence of disseminated plasma leakage such as pleural effusion, ascites and hypoalbuminemia(1).

Acute visual loss in a patient with DF is an unusual occurrence, which generally arises due to hemorrhagic complications in the retina ${ }^{(2)}$ or to virus-related optic neuritis ${ }^{(3,4)}$. Visual loss from intracranial complications of diseases involving the optic pathways is extremely rare, but was recently described in two patients with hemorrhage in pituitary adenomas $^{(1,4)}$.

In this paper we document, to our knowledge, the first reported case of DF and bilateral acute visual loss caused by chiasmal compression from Rathke's cleft cyst (RCC) apoplexy.

\section{CASE REPORT}

A 47-year-old man was referred for evaluation of acute bilateral visual loss, most severe in the left eye (OS). One month prior to examination, the patient had experienced rapidly progressing blurred vision over a period of three days, associated with headache, retro-ocular pain, fever and prostration. A medical evaluation at another facility suggested the diagnosis of DF, which was subsequently confirmed by positive serologic testing for dengue virus-specific lgM antibodies. The visual complaints were apparently considered unspecific symptoms because of generalized malaise. In addition, a positive tourniquet test indicated a hemorrhagic tendency. As there were no signs of dengue shock syndrome, and the patient was advised to hydrate, rest, and watch for warning signs of complications of DF.

The systemic symptoms gradually resolved, but the blurred vision improved only slightly and the patient was referred for ophthalmic evaluation. His past medical history was unrevealing, except for the use of glasses for the preceding 30 years and slightly decreased vision due to anisometropic amblyopia in the right eye (OD) since childhood. On ophthalmic examination, the best-corrected visual acuity was $20 / 60$ in OD (+3.75 sph X -0.75 cyl axis 80$)$ and 20/300 in OS (+0.25 sph). The pupils were equal in size but a slight relative afferent pupillary defect was observed on the left side. The slit lamp findings and intraocular pressure measurements were within normal limits. Ophthalmoscopy was normal except for mild temporal optic disc pallor in OS. The visual field (VF) examination demonstrated loss of the temporal field in both eyes and constriction of the inferior nasal field in OS (Figure 1). Optical coherence tomography revealed peripapillary retinal nerve fiber layers of normal thickness in both eyes. Magnetic resonance imaging (MRI) revealed a tumor in the sellar region with extension to the suprasellar cistern and compressing the optic chiasm. Heterogeneous areas in the tumor suggested intralesional bleeding. The lesion showed a hyperintense signal on T1-weighted images and a hypointense signal on T2-weighted images, indicating hemorrhage inside the cystic tumor (Figure 2). Subsequently, the patient developed nausea and vomiting. A repeat laboratory investigation revealed a marked decrease in cortical and adrenocorticotrophin (ACTH) hormone levels, indicating adrenal insufficiency. The patient was submitted to urgent transsphenoidal surgery. The histological characteristics of the tumor were consistent with RCC (Figure 3).
Submitted for publication: October 10, 2013

Accepted for publication: January 3, 2014

Study conducted at the Department of Ophthalmology and Otolaringology, University of São Paulo Medical School.

Division of Ophthalmology, University of São Paulo Medical School, São Paulo, Brazil.
Funding: No specific financial support was available for this study.

Disclosure of potential conflicts of interest: None of the authors have any potential conflicts of interest to disclose.

Corresponding author: Ana Claudia De Franco Suzuki. Av. Dr. Eneas de Carvalho Aguiar, 255 6o andar - sala 6121 - São Paulo - SP - 05403-000 - Brazil - Email: anacsuzuki@gmail.com 


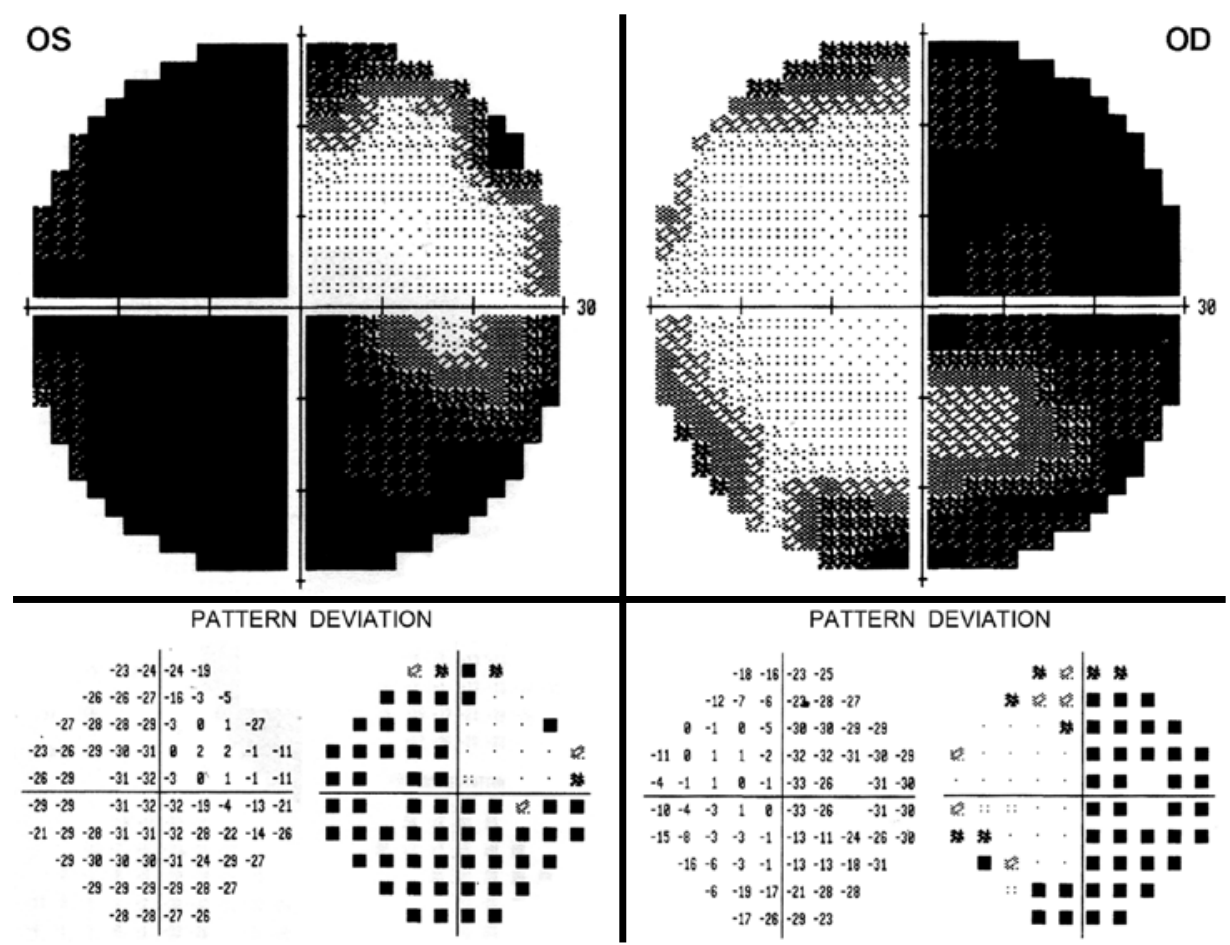

Figure 1. Automated static perimetry (Humphrey 24-2SITA-Standard test), gray scale (above) and pattern deviation (below), showing complete temporal field loss in both eyes, some nasal field constriction in the right eye (OD) and severe inferior and nasal loss in the left eye (OS).

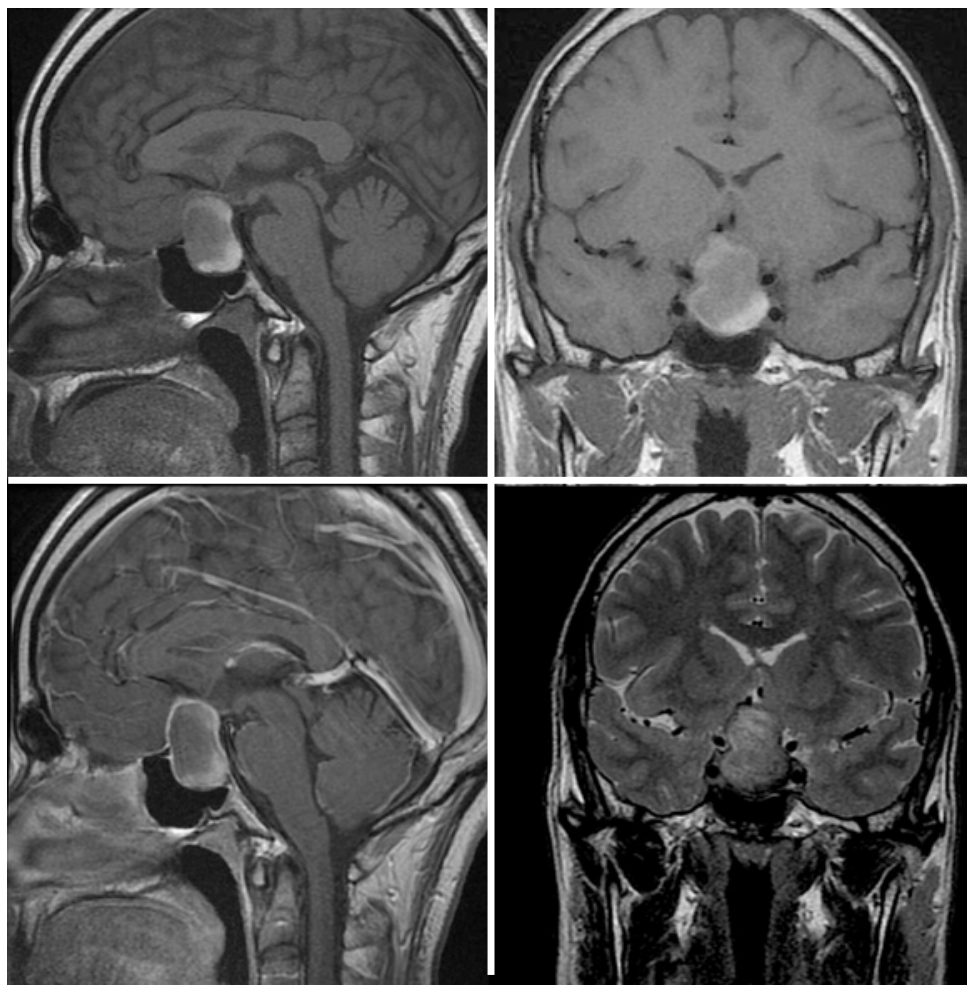

Figure 2. Magnetic resonance imaging scan showing a cystic sellar and suprasellar tumor with chiasmal compression. There were areas of hyperintense signal on T1-weighted images on sagittal (upper left) and coronal (upper right) sections. The lesion has a similar appearance on contrasted T1-weighted image, after gadolinium injection (lower left) and shows hypointense signal on coronal T2-weighted image (lower right). Observe that the hyperintense (on T1) and hypointense (on T2) areas are present in the lower and posterior part of the lesion, compatible with hemorrhage. 


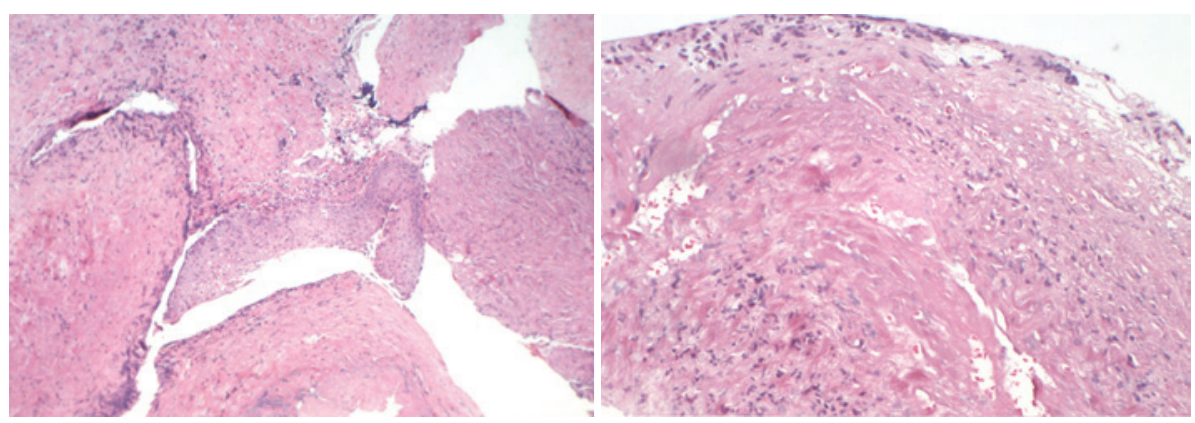

Figure 3. Histopathological study indicative of Rathke's cleft cyst. Above: a thick, collagenous wall and areas of squamous metaplasia $(\mathrm{H} \& \mathrm{E}, \times 50)$. Below: Simple surface epithelium of Rathke's cleft cyst, composed of well-differentiated, columnar, and nondescriptive cells (H\&E, x200).

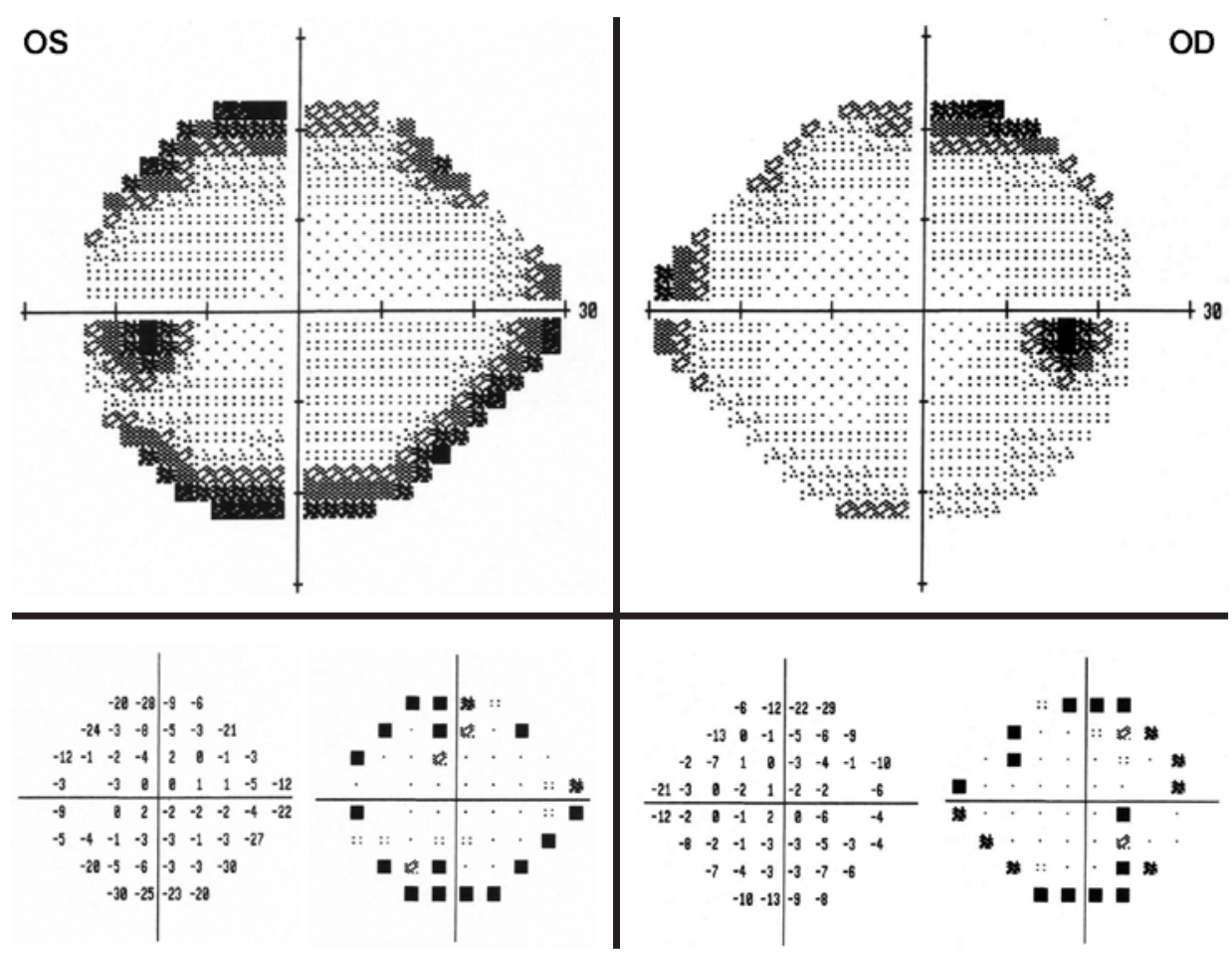

Figure 4. Automated static perimetry (Humphrey 24-2 SITA-Standard test), gray scale (above), and pattern deviation (below), showing 2 weeks after surgery, with only a peripheral, predominantly upper temporal depression in the right eye (OD) as well as in the left eye (OS).

Shortly after surgery, vision and systemic symptoms improved markedly. Two weeks after surgery, visual acuity improved to 20/30 in OD and 20/20 in OS. A repeat VF examination revealed only mild depression, predominantly upper temporal, in both eyes (Figure 4). A repeat MRI scan revealed marked reduction of the suprasellar mass and complete decompression of the visual pathway.

\section{DISCUSSION}

RCC is a benign and usually asymptomatic epithelial sellar lesion that develops as a result of incomplete obliteration of Rathke's pouch. Histologically, RCCs present a single layer of ciliated cuboidal or columnar epithelium and often contain goblet, squamous, and basal cells. Histopathological confirmation is required for diagnosis. RCCs are found in $13-22 \%$ of autopsies of patients with normal pituitary. Infrequently, when the cysts become larger and compress the pituitary and surrounding structures, patients may develop headaches, endocrinopathies, and visual disturbances secondary to lesion extension ${ }^{(6)}$.

A rare presentation of symptomatic RCCs is hemorrhage into the cyst, which mimics the clinical syndrome of pituitary tumor apople$x y$, with acute worsening or new onset of the described symptoms. Recently, Chaiban et al. ${ }^{(6)}$ reviewed the database at their institution and the PubMed database with regard to RCC apoplexy. At their institution, RCC represented $7 \%$ of surgically treated sellar lesions, and RCC apoplexy was the first manifestation in 20\% of these. The mean age of presentation was 40.2 years (range 16-70 years), with a female/ male ratio of $15: 5^{(6)}$. The clinical presentation of RCC apoplexy includes acute headaches, VF loss, decreased visual acuity, cranial nerve palsies, pituitary dysfunction, and occasionally altered mental status. Severe headaches seem to be the most frequent symptom. On MRI, the appearance of RCCs may vary depending on the mucopolysaccharide content of the cyst and the presence of hemorrhage or blood 
clots. Yet, hemorrhage into the cyst most often appears as an area of signal hyperintensity on T1-weighted noncontrast images. Without the aid of surgical and histopathological findings, this condition is very difficult to distinguish from pituitary tumor apoplexy (unless the patient is known to have a RCC) $)^{(6,7)}$. In cases of RCC apoplexy with visual impairment or hypopituitarism, transsphenoidal surgery is the treatment of choice. Long-term follow up is required to monitor pituitary function and because of the potential for recurrence of apoplexy.

Our case draws attention to the need to broaden the differential diagnosis of causes of visual loss in patients with DF. While the possibility of visual loss from virus-related hemorrhagic or inflammatory retinal and optic nerve conditions is generally appreciated, hemorrhagic complications in other parts of the visual pathway are uncommon and not widely recognized. The condition should, however, be promptly recognized to prevent further permanent visual loss. While our patient fortunately experienced dramatic visual improvement after surgery, a late diagnosis would most likely have led to permanent optic pathway damage. The pathogenesis of RCC apoplexy is not completely understood, but arterial ruptures in its single-layer epithelium or in compressed portal veins due to possible blood pressure fluctuations are the suggested mechanisms ${ }^{(8)}$. However, in our case, the precipitating mechanism was likely dengue-related blood dyscrasia in a predisposed individual. Dengue hemorrhagic fever is one important cause of low platelet count that may lead to spontaneous bleeding from mucosal surfaces. Although our patient did not have other systemic hemorrhagic complications, the positive tourni- quet test clearly indicated that he had the hemorrhagic form of the disease that was manifested solely by bleeding inside the cyst and subsequent hypopituitarism from secondary endocrine dysfunction.

In conclusion, this report emphasizes that visual loss in patients with DF may occur not only from ocular complications but also from acute enlargement of suprasellar tumors, including not only pituitary apoplexy but also cleft cyst apoplexy.

\section{REFERENCES}

1. Wildemberg LE, Neto LV, Niemeyer P, Gasparetto EL, Chimelli L, Gadelha MR. Association of dengue hemorrhagic fever with multiple risk factors for pituitary apoplexy. Endocr Pract. 2012;18(5):e97-e101.

2. Preechawat $P$, Poonyathalang A. Bilateral optic neuritis after dengue viral infection. J Neuroophthalmol. 2005;25(1):51-2.

3. Aragao RE, Barreira IM, Lima LN, Rabelo LP, Pereira FB. [Bilateral optic neuritis after dengue viral infection: case report]. Arq Bras Oftalmol. 2010;73(2):175-8. Portuguese.

4. Kumar V, Kataria R, Mehta VS. Dengue hemorrhagic fever: a rare cause of pituitary tumor hemorrhage and reversible vision loss. Indian J Ophthalmol. 2011;59(4):311-2.

5. Haritoglou C, Dotse SD, Rudolph G, Stephan CM, Thurau SR, Klauss V. A tourist with dengue fever and visual loss. Lancet, 2002;360(9339):1070. Comment in: Lancet. 2003; 361(9352):181-2.

6. Chaiban JT, Abdelmannan D, Cohen M, Selman WR, Arafah BM. Rathke cleft cyst apoplexy: a newly characterized distinct clinical entity. J Neurosurg. 2011;114(2):318-24.

7. Binning MJ, Liu JK, Gannon J, Osborn OG, Couldwell WT. Hemorrhagic and nonhemorrhagic Rathke cleft cysts mimicking pituitary apoplexy. J Neurosurg. 2008;108(1):3-8.

8. Kim E. A Rathke's cleft cyst presenting with apoplexy. J Korean Neurosurg Soc. 2012; 52(4):404-6.

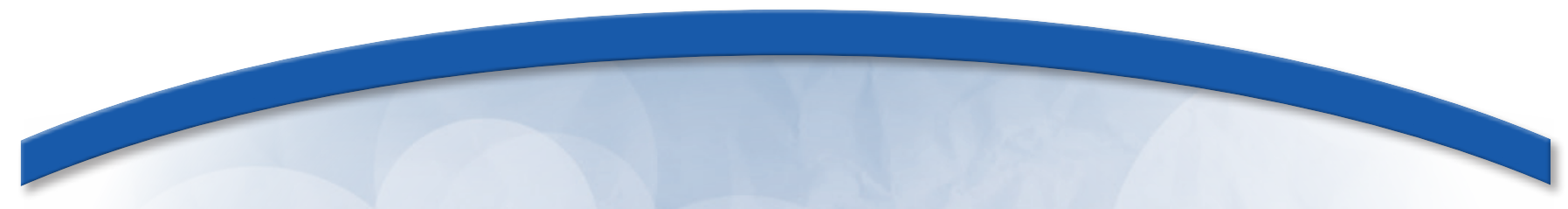

\title{
$38^{\circ}$ Simpósio Internacional Moacyr Ấlvaro - SIMASP
}

\author{
5 a 7 de março de 2015 \\ Maksoud Plaza Hotel
}

São Paulo - SP

Informações:

Tel.: (11) 5081-7028

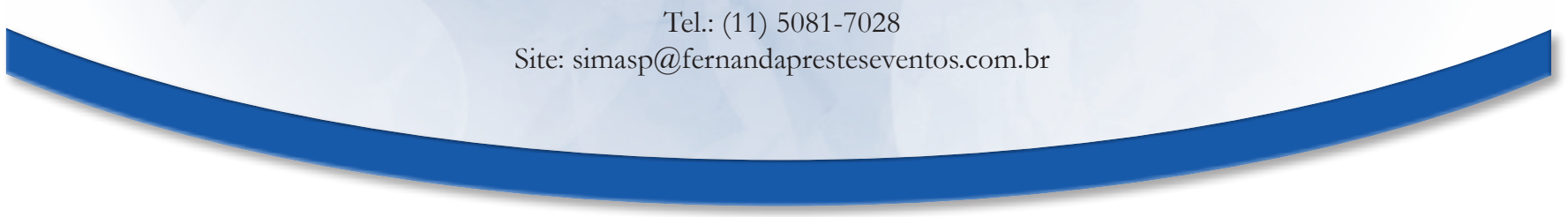

